\title{
Methicillin resistant Staphylococcus aureus outbreak in a neonatal intensive care unit
}

\author{
Seema Irfan, ${ }^{1}$ Imran Ahmed, ${ }^{1}$ Farida Lalani, ${ }^{2}$ Naureen Anjum, ${ }^{3}$ Nadia Mohammad, ${ }^{3}$ Maria Owais ${ }^{4}$ and Afia Zafar ${ }^{1}$
}

${ }^{1}$ Department of Pathology \& Laboratory Medicine, Aga Khan University Hospital, Karachi, Pakistan. ${ }^{2}$ Department of Microbiology, Armed Forces Institute of Pathology, Rawalpindi, Pakistan. ${ }^{3}$ Department of Obstetrics \& Gynecology and Paediatrics, Aga Khan Secondary Hospital, Karachi, Pakistan. 4Ziauddin Medical University, Karachi, Pakistan. (Correspondence to: Seema Irfan: seema.irfan@aku.edu).

\begin{abstract}
The global and national burden of communicable and noncommunicable diseases continues to rise, thus making access to Healthcare workers (HCWs) colonized with methicillin-resistant Staphylococcus aureus (MRSA) may pose transmission risk to vulnerable patients including neonates. This study reports an MRSA outbreak in a level-II neonatal intensive care unit (NICU) of a secondary care hospital in Pakistan. Once identified, an infection control team from the parent hospital visited the facility, risk factors were listed and infection control measures taken to control the outbreak. Screening cultures of NICU staff and environmental cultures from NICU were obtained for the presence of MRSA. Five neonates were positive for MRSA; one HCW was found to be colonized with MRSA, the antibiogram pattern of which matched with that of the outbreak strain. Decolonization of colonized HCWs and re-deployment from NICU to outpatient department were taken and the outbreak was declared over once no further MRSA cases were identified. Identification of an outbreak situation is the cornerstone for its control and multiple measures taken simultaneously help in curbing the outbreak. Although an epidemiological link was established with the HCW, a molecular link could not be proven.

Keywords: outbreak; MRSA; NICU; health care worker, Pakistan

Citation: Irfan S; Ahmed I; Lalani F; Anjum N; Mohammad N; Owais M; et al. Methicillin resistant Staphylococcus aureus outbreak in a neonatal inten-

sive care unit. East Mediterr Health J. 2019;25(7):514-518 https://doi.org/10.26719/emhj.18.058
\end{abstract}

Received: 07/08/17; accepted: 07/11/17

Copyright (C) World Health Organization (WHO) 2019. Some rights reserved. This work is available under the CC BY-NC-SA 3.o IGO license (https:// creativecommons.org/licenses/by-nc-sa/3.o/igo).

\section{Introduction}

Neonatal intensive care unit (NICU) patients are at high risk of acquiring colonization and infection by Methicillin-resistant Staphylococcus aureus (MRSA) (1). MRSA in NICUs was first reported in 1981 (2); since then, the organism has been reported regularly in this age group and several outbreaks have been reported globally $(3,4)$. Hospital-acquired MRSA infections in neonates can cause a variety of diseases including blood stream infections, meningitis, brain abscess, pneumonia, osteomyelitis, infective arthritis, skin and soft tissue infections, conjunctivitis and endocarditis, and leading to serious morbidity and mortality. The role of health care workers (HCWs) has been cited in the nosocomial transmission of MRSA (5) and poor infection control practices have also been implicated in its acquisition and transmission (6). Routine decolonization of asymptomatic HCWs is not recommended unless they have been identified as a source of an outbreak (7). There are several other studies that report cessation of nosocomial MRSA outbreaks after proper decolonization of HCWs (8-10).

This is a report of an MRSA outbreak in a neonatal care unit of a local secondary care hospital during the period 6 November to 31 December 2013. The source of this outbreak was traced to a HCW and the aim of this observational study is to highlight the importance of implementation of infection prevention /control measures and limitations for controlling an outbreak.

\section{Ethical considerations}

The study was provided an exemption by the Ethics Review Committee of the Aga Khan University, Karachi, Pakistan (ERC \# 4693-Pat-ERC-17).

\section{Outbreak report}

\section{Setting}

The MRSA outbreak occurred in a secondary care hospital of the Aga Khan University Hospital (AKUH), Karachi, Pakistan. The facility conducts around 3000 deliveries annually. The hospital has 45 beds in total with level-I and -II neonatal intensive care units. There are about 600 admissions to the NICU annually. Level-II NICUs provide care to neonates of $\geq 32$ weeks or $\geq 1500 \mathrm{~g}$ that have physiological immaturity or neonates that are moderately ill with problems that are expected to be resolved. Level-I NICUs provide neonatal resuscitation at every delivery and care for neonates born at 35-37 weeks that are physiologically stable.

The level-II NICU of secondary care hospital comprises a single room with one entrance/exit door, used by both mothers and HCWs. A small feeding area where mothers feed their babies is also present in the same room. Because of limited space, there was often overcrowding. There are three incubators and two cots in the NICU and has the capacity of admitting five neonates in total. However, because of limited beds and increased 
load, this number is often exceeded resulting in a mismatch between patient and nurse numbers. Neonates are fed as required and bottles and the weighing machine are disinfected during every shift. Diapers are changed as required.

Staphylococcus aureus was grown on chocolate and sheep blood agar (for blood culture and pus specimen) or cysteine lactose electrolyte deficient agar (for urine specimen). Growth characteristics and colony gram stain were observed. Catalase and slide coagulase tests were performed for preliminary identification followed by tube coagulase according to the standard protocols (11). Susceptibility testing was performed as prescribed by Clinical and Laboratory Standards Institute (12). The outbreak included a total number of five neonates whom cultures were positive for MRSA.

\section{Index Case}

The first neonate was born on 4 November, 2013, in the secondary care hospital by elective caesarean section at 38 weeks due to history of previous caesarean section and gestational diabetes mellitus (mother on insulin). The neonate was shifted to NICU due to transient tachypnea of newborn and grunting; blood culture was sent, which grew MRSA.

The second neonate was admitted the next day (5 November) at 48 hours of life because of jaundice, and had been delivered vaginally at term. Urine culture that was sent as part of workup for jaundice and sepsis was found to be positive for MRSA.

The third neonate was admitted on 21 November, 2013, from a clinic at 48 hours of life because of fever, and had been delivered vaginally at term in hospital and was discharged home on first day of life. In this neonate, MRSA grew in urine culture.

The fourth neonate was admitted on 23 November, 2013, at 26 hours of life because of jaundice and had been delivered vaginally at term and also had MRSA positive in urine culture.

The fifth neonate was delivered by elective caesarean section on 20 November, 2013, and was kept in a wellbaby nursery for three days. This neonate was admitted on fourth day of life to the nursery due to fever and excessive crying. The neonate developed intravenous catheter site abscess and a pus culture was sent and reported positive for MRSA.

Initial suspicion of outbreak was made when urine culture of 2nd neonate was reported positive on 7 November, 2013. At this point, in addition to the standard protocol of isolation of colonized or infected neonates, other immediate infection control steps were implemented by nursery staff including strict adherence to hand hygiene by alcohol-based hand sanitizers or soap and water. A check was put on traffic control in the nursery allowing only parents of admitted neonates. Doors were kept locked so that no-one could enter without permission in the nursery, operation theatre and labour room. Protocols were re-emphasized for terminal cleaning of all patient care areas.
On 21 November, 2013, the urine culture of the third neonate was reported positive for growth of MRSA and within 4 days the 4 th and 5th neonates were also found to be culture positive. At this point infection control committee members visited the nursery, labour room and operation theatre from which environmental cultures were taken. The rest of the neonates admitted in the nursery were also screened for MRSA during the period of outbreak investigation. In addition, the entire nursery staff was screened. Specimens were taken from their nares, hairline and hands. Extensive training of housekeeping staff, including cleaning of surfaces and frequently touched areas, was stressed. Strict infection control measures were taken during the outbreak and were followed up thereafter. Paramedical staff and physicians of NICU and wards were reinforced to follow proper hand washing techniques and frequency of hand wash as per WHO recommendations (13).

Already sick neonates had priority care and new admissions to NICU were suspended until discharge of currently admitted neonates. All neonates with a culture positive for MRSA were placed under contact precautions and isolated to avoid further spread. As the neonates were already on vancomycin, which was changed on the basis of culture report, none deteriorated and were discharged home in a stable condition. On follow-up visits they were found to be healthy.

Additional measures implemented included avoidance of overcrowding. To facilitate this, admission has now been limited to its capacity, number of alcohol based hand sanitizers had been increased and placed in between each incubator, and a fixed time had been designated for visitors.

All screening cultures from other admitted neonates as well as environmental cultures were found to be negative. MRSA was detected in nasal cultures of one nurse while remaining staff cultures were found negative. The susceptibility pattern of the MRSA isolated from the HCW was in concordance with the susceptibility pattern of outbreak isolates derived from clinical samples of five neonates (Table 1). The HCW was recommended to have decolonization therapy, which included a fiveday course of mupirocin nasal ointment twice a day and daily chlorhexidine bath. She was moved from the nursery to the outpatient clinic, which is considered as a low risk area with minimal patient contact. After the decolonization course, a nares sample was cultured as evidence of clearance from MRSA colonization, which took place 10 days after decolonization therapy and was found negative and the HCW was allowed to carry on with regular duties. The outbreak came to an end after taking all these collective measures and no further cases have been reported since (Figure 1).

\section{Discussion}

This MRSA outbreak in a neonatal level-II nursery had been linked to the MRSA colonized HCW. Although molecular typing of MRSA isolate from neonates and staff 
Figure 1: MRSA isolation on quarterly (Q1-13 to Q4-15) basis from neonates admitted to nursery from 2013 to 2015.

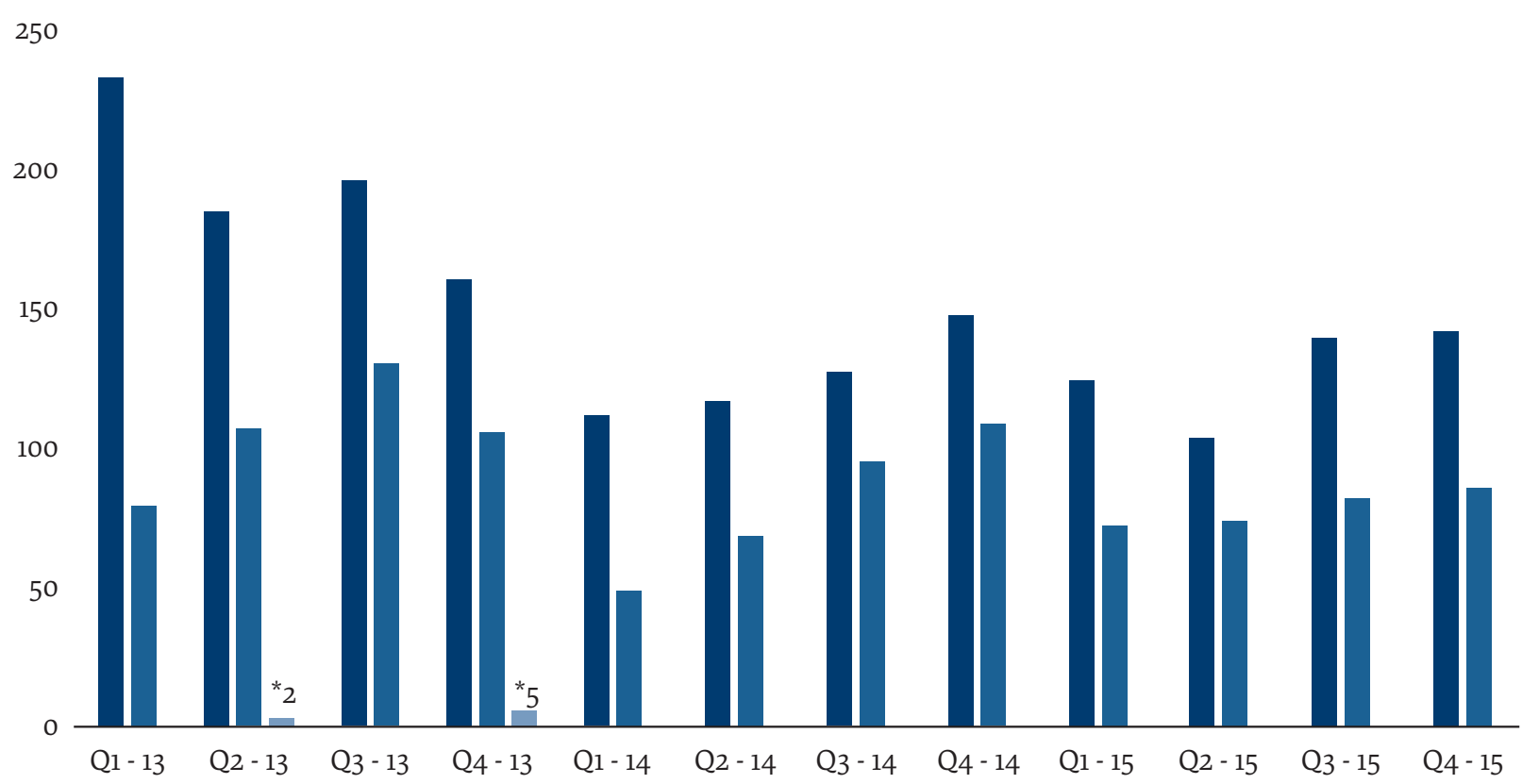

-Admissions —Culture sent — MRSA positive

${ }^{*}$ Numbers of MRSA positive cases in 2nd and 4th quarters of 2013 are shown above the bars

\begin{tabular}{|c|c|c|c|c|c|c|}
\hline Antibiotic & $\begin{array}{l}\text { Patient-1 } \\
\text { (blood } \\
\text { culture) }\end{array}$ & $\begin{array}{l}\text { Patient-2 } \\
\text { (urine } \\
\text { culture) }\end{array}$ & $\begin{array}{l}\text { Patient-3 } \\
\text { (urine } \\
\text { culture) }\end{array}$ & $\begin{array}{c}\text { Patient-4 } \\
\text { (Urine culture) }\end{array}$ & $\begin{array}{c}\text { Patient-5 } \\
\text { (Pus culture) }\end{array}$ & $\begin{array}{c}\text { Health care } \\
\text { worker } \\
\text { (MRSA Screen) }\end{array}$ \\
\hline Penicillin & $\mathrm{R}$ & NT & NT & NT & $\mathrm{R}$ & $\mathrm{R}$ \\
\hline Oxacillin & $\mathrm{R}$ & $\mathrm{R}$ & $\mathrm{R}$ & $\mathrm{R}$ & $\mathrm{R}$ & $\mathrm{R}$ \\
\hline Gentamicin & S & S & S & I & S & $\mathrm{s}$ \\
\hline Amikacin & $S$ & $S$ & S & $S$ & S & S \\
\hline Erythromycin & $S^{*}$ & NT & NT & NT & S & S \\
\hline Clindamycin & S & NT & NT & NT & $\mathrm{s}$ & $\mathrm{s}$ \\
\hline Cotrimoxazole & S & $\mathrm{s}$ & $\mathrm{s}$ & $\mathrm{s}$ & S & $\mathrm{s}$ \\
\hline Vancomycin & S & S & $S$ & S & S & S \\
\hline Ciprofloxacin & S & S & S & S & S & $S$ \\
\hline Fusidic acid & S & NT & NT & NT & S & S \\
\hline Tetracycline & $S^{*}$ & $S^{*}$ & $S^{*}$ & $S^{*}$ & $S^{*}$ & $\mathrm{~s}$ \\
\hline
\end{tabular}

MRSA = Methicillin resistant Staphylococcus aureus. $S=$ susceptible. $R=$ resistant. $I=$ intermediate. $N T=$ not tested. ${ }^{*}=$ not reported.

could not be performed, this remains a plausible explanation as no further cases were reported after the HCW was identified and removed temporarily from direct dealing with patients. Furthermore, the antimicrobial susceptibility pattern of MRSA isolated from the HCW also matched with the MRSA isolates from the neonates.

The epidemiology of MRSA in NICU can be extremely complex because outbreaks can overlap endemic circulation, and tracing the transmission routes is therefore considered to be challenging (14). NICU surveillance data for 2013 shows two MRSA isolates during the second quarter $(1.8 \%$ out of 107 cultures sent), reflecting the possibility of endemic circulation (Figure 1). However, a sudden rise in the number of MRSA cases during the fourth quarter of 2013 (5 MRSA cases [4.7\%] out of 106 culture requests) would fit with an outbreak definition.

Among five MRSA culture positive neonates, one had growth in blood and one in pus aspirate, which was collected from the catheter insertion site, while three neonates had MRSA growth in urine. The clinical condition of first and fifth neonate was consistent with 
MRSA sepsis (supported by blood and pus aspirate culture results). In the remaining three cases, the blood culture was reported negative while urine culture grew MRSA. These three neonates were discharged after a short stay in NICU; therefore, evidence for the MRSA sepsis was weak.

Although difficult to prove in retrospect, the positive urine cultures might represent contamination of specimen during collection from the colonized perineal area of neonates. Blood cultures for all three were negative. For the neonate testing positive for MRSA from the blood culture, it could be due to colonization followed by entry into the bloodstream through a minor break in the skin or through colonization of the respiratory tract. Although colonization was a possibility for neonates that had only a positive urine culture for MRSA, vancomycin was added to their treatment regimen.

The literature indicates that in multiple outbreaks, HCWs have been involved in the transfer of MRSA to patients. A review article reported mean nasal MRSA carriage of $4.1 \%$ among hospital staff in 104 studies. Furthermore, the same review also described transmission of MRSA from HCWs to patients. One hundred and six studies were evaluated, from which 27 studies demonstrated clear molecular evidence of MRSA transmission from HCWs to patients, while 52 studies where typing was not performed, transmission was considered likely (5). Similar to the current report, there are several studies that have reported cessation of an outbreak after proper decolonization of HCWs; however, effects of other simultaneous infection control measures could not be ruled out $(8-10)$.
Risk factors for MRSA carriage in HCWs include cutaneous lesions or conditions such as dermatitis, eczema, sinusitis, rhinitis, chronic otitis externa, etc. Work-related factors include work experience, area of service (e.g. medicine, surgery, long-term care facilities), employment in areas where MRSA is endemic, close contact with patients (e.g. wound contact), poor infection control practices (e.g. poor hand hygiene), and high work load. Decolonization with mupirocin ointment in an outbreak setting is recommended for HCWs carrying MRSA (7). In the current study the colonized HCW was treated successfully with mupirocin nasal ointment along with chlorhexidine baths. Mupirocin susceptibility testing was not performed for this outbreak of MRSA isolates. However, previously published data from AKUH clinical laboratory show low minimum inhibitory concentrations for MRSA isolates against mupirocin, which helped predict the treatment response in this case (15).

\section{Recommendations}

We could only establish an epidemiological link of the outbreak with the colonized HCW. Typing of MRSA strains could not be performed and thus a molecular link was not ascertained. It is imperative that infection control measures should be taken prudently at all times. In case of an outbreak, these measures must be re-emphasized and environmental cultures should be taken along with screening of the HCW.

Funding: None.

Competing interests: None declared.

\section{Flambée épidémique de Staphyloccocus aureus résistant à la méthicilline dans une unité de soins intensifs néonatals}

\section{Résumé}

Les agents de santé colonisés par le Staphyloccocus aureus résistant à la méthicilline (SARM) peuvent poser un risque de transmission aux patients vulnérables, y compris les nouveau-nés. La présente étude fait état d'une flambée de SARM dans une unité de soins intensifs néonatals (USIN) de niveau II d'un hôpital de soins secondaires au Pakistan. Une fois identifiée, une équipe de lutte contre l'infection de l'hôpital mère a visité l'établissement, y a dressé la liste des facteurs de risque et pris des mesures pour endiguer l'infection en vue de juguler la flambée. Des cultures de dépistage sur le personnel de l'unité de soins intensifs de néonatalogie et des cultures environnementales de l'USIN ont été obtenues pour détecter la présence du SARM. Cinq nouveau-nés étaient positifs au SARM; un agent de santé a été colonisé par le SARM, dont l'antibiogramme correspondait à celui de la souche de la flambée. La décolonisation des agents de santé colonisés et leur transfert de l'unité de soins intensifs néonatals vers le service de consultation externe ont été réalisés et la flambée a été déclarée terminée lorsque aucun autre cas de SARM n'a été identifié. L'identification de la situation de la flambée est la pierre angulaire de l'action de lutte et de multiples mesures prises simultanément aident à enrayer la flambée. Bien qu'un lien épidémiologique ait été établi avec l'agent de santé, un lien moléculaire n’a pu être prouvé.

$$
\begin{aligned}
& \text { حدوث وباء المكورات العنقودية الذهبية المقاومة للميثيسيلين في وحدة الرعاية المركزة لحديثي الولادة }
\end{aligned}
$$

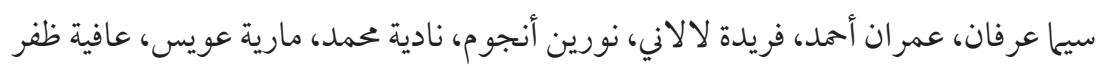

$$
\begin{aligned}
& \text { الخلاصة }
\end{aligned}
$$

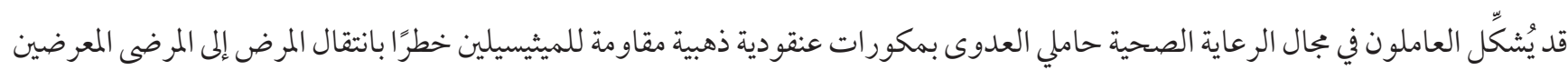

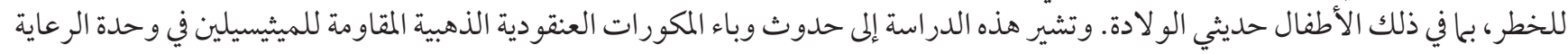




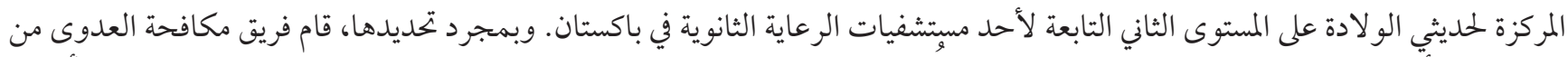

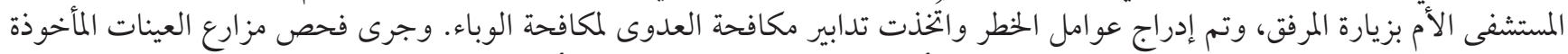

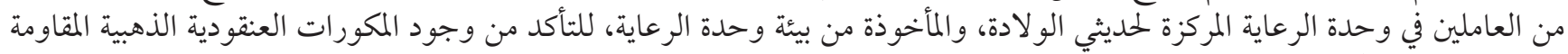

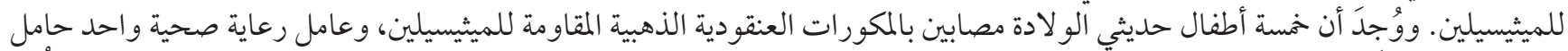

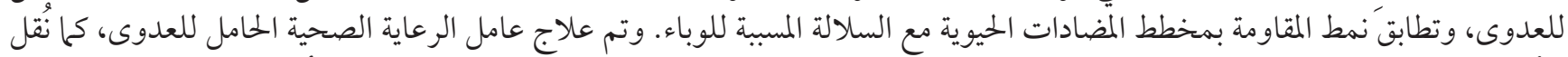

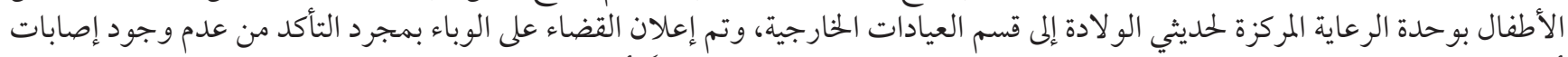

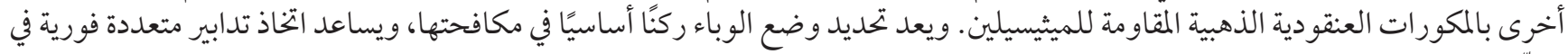

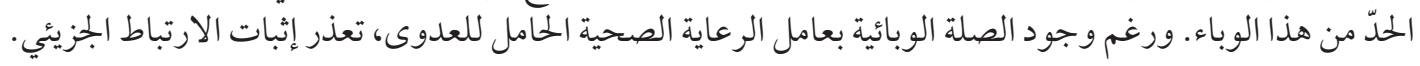

\section{References}

1. Giuffrè M, Bonura C, Cipolla D, Mammina C. MRSA infection in the neonatal intensive care unit. Expert Rev Anti Infect Ther. 2013;11(5):499-509. http://dx.doi.org/10.1586/eri.13.28

2. Weeks JL, Garcia-Prats JA, Baker CJ. Methicillin-resistant Staphylococcus aureus osteomyelitis in a neonate. JAMA. 1981;245(16):1662-4. http://dx.doi.org/10.1001/jama.1981.03310410040025

3. Saiman L, Cronquist A, Wu F, Zhou J, Rubenstein D, Eisner W, et al. An outbreak of methicillin-resistant Staphylococcus aureus in a neonatal intensive care unit. Infect Control Hosp Epidemiol. 2003;24(5):317-21. http://dx.doi.org/10.1086/502217

4. Iacobelli S, Colomb B, Bonsante F, Astruc K, Ferdynus C, Bouthet MF, et al. Successful control of a Methicillin-resistant Staphylococcus aureus outbreak in a neonatal intensive care unit: a retrospective, before-after study. BMC Infect Dis. 2013;13(1):440. http://dx.doi.org/10.1186/1471-2334-13-440

5. Albrich WC, Harbarth S. Health-care workers: source, vector, or victim of MRSA? Lancet Infect Dis. 2008;8(5):289-301. http:// dx.doi.org/10.1016/S1473-3099(08)70097-5

6. Grundmann H, Hori S, Winter B, Tami A, Austin DJ. Risk factors for the transmission of methicillin-resistant Staphylococcus aureus in an adult intensive care unit: fitting a model to the data. J Infect Dis. 2002;185(4):481-8. http://dx.doi.org/10.1086/338568

7. Siegel JD, Rhinehart E, Jackson M, Chiarello L, Healthcare Infection Control Practices Advisory Committee. Management of multidrug-resistant organisms in healthcare settings, 2006. Am J Infect Control. 2007 Dec;35(10 Suppl 2):S165-93. http://dx.doi. org/10.1016/j.ajic.2007.10.006 PMID: 18068814

8. Davies EA, Emmerson AM, Hogg GM, Patterson MF, Shields MD. An outbreak of infection with a methicillin-resistant Staphylococcus aureus in a special care baby unit: value of topical mupirocin and of traditional methods of infection control. J Hosp Infect. 1987;10(2):120-8. http://dx.doi.org/10.1016/0195-6701(87)90137-X

9. Wang JT, Lin SF, Chiu HL, Wang LC, Tai HM, Jiang CF, et al. Molecular epidemiology and control of nosocomial methicillin-resistant Staphylococcus aureus infection in a teaching hospital. J Formos Med Assoc. 2004;103(1):32-6.

10. Harberg D. Society for Healthcare Epidemiology of America guideline approach works to control a methicillin-resistant Staphylococcus aureus outbreak. Infect Control Hosp Epidemiol. 2005;26(2):115-6. http://dx.doi.org/10.1086/503509

11. Washington Winn Jr. Stephen Allen, William Janda, Elmer Koneman, Gary Procop, Paul Schredkenberger, Gail Woods. Koneman's Color Atalas and Textbook of Diagnostic Microbiology. 6th ed. United States of America: Lippincott Williams \& Wilkins; 2006.

12. CLSI. Performance Standards for Antimicrobial Susceptibility Testing; Twenty-Third Informational Supplement. CLSI Document MiooS-23. Wayne, PA: Clinical and Laboratory Standards Institute; 2013.

13. World Health Organization. Five moments for hand hygiene. Geneva: World Health Organization; 2016 (http://www.who.int/ gpsc/tools/Five_moments/en/).

14. Faibis F, Laporte C, Fiacre A, Delisse C, Lina G, Demachy MC, et al. An outbreak of methicillin-resistant Staphylococcus aureus surgical-site infections initiated by a healthcare worker with chronic sinusitis. Infect Control Hosp Epidemiol. 2005;26(2):213-5. http://dx.doi.org/10.1086/502529

15. Nizamuddin S, Irfan S, Zafar A. Evaluation of prevalence of low and high level mupirocin resistance in methicillin resistant Staphylococcus aureus isolates at a tertiary care hospital. J Pak Med Assoc. 2011;61(6):519-21. 